\title{
Ultrasound remission in patients with rheumatoid arthritis in clinical remission
}

\author{
Rym Fakhfakh, Nejla Elamri, Khadija Baccouche, Sadok Laataoui, Hela Zeglaoui, Elyes Bouajina \\ Department of Rheumatology, Farhat Hached Hospital, University of Medicine of Sousse, Tunisia
}

\begin{abstract}
Objectives: The aim of the study was to assess ultrasound (US) remission in patients with rheumatoid arthritis (RA) in clinical remission using different definitions.

Material and methods: This was a cross-sectional study including patients with RA in clinical remission defined by disease activity score (DAS28)-erythrocyte rate (ESR) $\leq 2.6$ for at least 6 months. Each patient underwent B-mode and power Doppler (PD) assessments of 42 joints and 20 tendons. B-mode and PD signal for synovitis and tenosynovitis (TS) were defined and graded semi-quantitatively (0-3) according to the outcome measures in rheumatology clinical trials (OMERACT). Several different definitions of US remission were examined: the absence of synovial hypertrophy (SH), TS on B-mode and PD signal, the absence of SH and PD signal, a grade $\leq 1$ of $\mathrm{SH}$ and the absence of $\mathrm{PD}$, a grade $\leq 1$ of $\mathrm{SH}$ and $\mathrm{PD}$, the absence of $\mathrm{PD}$, or a grade of $\mathrm{PD} \leq 1$. The DAS28, clinical disease activity index (CDAI), simple disease activity index (SDAI), and the Boolean American College of Rheumatology/European League Against Rheumatism (ACR/EULAR) remission criteria were compared.

Results: Thirty-seven patients were enrolled. The rate of remission according to the different composite indices was $70.2 \%$ for the SDAI, $64.8 \%$ for the CDAl, and $54 \%$ for the ACR/EULAR Boolean criteria. Synovial hypertrophy and TS in B-mode were detected in $94.6 \%$ and $40.5 \%$ of patients, respectively. Synovitis with PD signal was found in $59.5 \%$ and $13.5 \%$ of patients had TS with PD, respectively. Ultrasound remission at joints and tendons was found in $5.4-62.2 \%$ of patients. For the other remission criteria: CDAI, SDAI, and ACR/EULAR Boolean criteria, 7.7-60\% of patients showed US remission at joints and tendons.

Conclusions: Clinical remission, even classified by strict composite indices, does not seem to be the closest method to the concept of absence of inflammatory activity; hence the interest of integrating US in assessing remission in practice.
\end{abstract}

Key words: ultrasonography, rheumatoid arthritis, remission.

\section{Introduction}

Rheumatoid arthritis (RA) is a chronic autoimmune disease characterized by the presence of erosive synovitis resulting in progressive joint damage, impaired function, and increased morbidity and mortality. Considerable progress in early diagnosis and therapeutic strategy for RA has been made in the last few decades. The persistent remission target has become achievable through advances in disease-modifying anti-rheumatic drugs (DMARDs) (the targeted synthetics - tsDMARDs, and biologics - bDMARDs), the tight-control and treat to target strategy [1, 2].

Clinical remission is evaluated by composite indices disease activity score (DAS28), simple disease activity index (SDAI), clinical disease activity index (CDAI), or the American College of Rheumatology/European League Against Rheumatism (ACR/EULAR) Boolean criteria, which combine clinical and laboratory assessment [3].

Nevertheless, despite apparent clinical remission, relapse is reported in $30-50 \%$ of patients in the first

Address for correspondence:

Rym Fakhfakh, Department of Rheumatoloogy, Farhat Hached Hospital, University of Medicine of Sousse, Rue Ibn El Jazzar, 4000 Sousse, Tunisia, e-mail: rymfakh@gmail.com

Submitted: 07.08.2021; Accepted: 08.11.2021 
2 years of remission [4] and joint damage progresses in 10-30\% [5]. These data suggest that composite indices may not reflect the real RA activity.

Ultrasound (US) in RA showed greater sensitivity than the clinical assessment to detect synovitis and tenosynovitis (TS) in B-mode and power Doppler (PD). Indeed, B-mode synovial hypertrophy (SH) was found in 33.3 to $100 \%$ of patients and PD signal was objectified in 14.9-93.3\% of patients in clinical remission [5].

Furthermore, US synovitis with PD predicted relapse, radiographic progression, and unsuccessful treatment tapering $[6,7]$. Several definitions were used for US remission, but none is consensual [8].

We aim through this article to assess US remission in patients with RA in clinical remission using different definitions.

\section{Material and methods}

Rheumatoid arthritis patients according to 2010 ACR/EULAR criteria [9] were recruited, consecutively, between January and December 2019 from the outpatient consultations or the day hospital of the Rheumatology Department. The patients were on conventional synthetic DMARDs (cSDMARDs) or bDMARDs.

They were included if they met the following criteria:

- RA diagnosed and patient was taken DMARD for more than 6 months,

- age greater than 18 years,

- clinical remission according to the DAS28 $\leq 2.6$ (using erythrocyte sedimentation rate - ESR) for at least 6 months and at the day of US examination,

- absence of flares in the last 6 months,

- same treatment for 6 months including the DMARDs, corticosteroids, and intraarticular injections.

The study was performed in accordance with the ethical standards of the responsible committee on human experimentation and with the Declaration of Helsinki. Informed consent was obtained from all patients before study enrolment.

\section{Clinical and laboratory assessment}

We recorded the patient demographics and RA characteristics as the presence of rheumatoid factor, anti-citrullinated peptide antibodies, and radiographic damage in hands and feet (using the modified Sharp score) [10].

On the day of US examination the patients were re-evaluated for disease activity. Tender joint counts (TJC), swollen joint counts (SJC), and patients' global assessment of disease activity and pain were rated on a numerical scale. Inflammatory markers, including C-reactive protein (CRP) and ESR, were performed during the week of evaluation. The investigator was blinded to the US findings.

\section{Clinical remission criteria}

As well as the DAS28, clinical remission was assessed according to the CDAI, the SDAI, and the ACR/EULAR Boolean criteria $(T J C \leq 1, S J C \leq 1, C R P \leq 10 \mathrm{mg} / \mathrm{dl}$ and patient global assessment $\leq 1$ ) [3].

\section{Ultrasound assessment}

A longitudinal and transverse examination of 42 joints and 20 tendon compartments was made for each patient on B-mode and PD using a My Lab ESAOTE US machine with a 6-18 MHz linear transducer. The operator was a rheumatologist experienced in musculoskeletal US and blind to data. The ultrasound assessments lasted 30-60 min.

The presence of $\mathrm{SH}$ in $\mathrm{B}$-mode and $\mathrm{PD}$ signal were examined in the following bilateral joints: glenohumeral (biceps sheath, posterior recess), elbow (radio-humeral and humero-ulnar joints), wrist (radiocarpal and distal radioulnar joints), dorsal side of the second to the fifth metacarpophalangeal (MCP), dorsal side of the second to fifth proximal interphalangeal of the hands, knees (anterior and parapatellar recesses), tibiotalar joint of the ankle, and dorsal side of second through fifth metatarsophalangeal joints.

The synovial hypertrophy or PD signal was attributed to the wrist when present in the radiocarpal or distal radioulnar joints. Similarly for the elbow if $\mathrm{SH}$ or synovial PD signal were identified in either the radio-humeral or humero-ulnar joints.

Tenosynovitis on B-mode and PD was assessed in hands, wrists, and ankles as follows: first through sixth extensor tendon compartments of the wrists, and second through fifth finger flexor digitorum superficialis and profundus tendons, tibialis posterior, and peroneal tendons.

For each joint, B-mode SH and PD signal was defined and scored separately, semiquantitively according to the outcome measures in rheumatology clinical trials (OMERACT) on a scale of $0-3$ (grade $0=$ none, grade $1=$ minimal, grade 2 = moderate, grade 3 = severe) [11].

The final score at each joint represented the maximal score for the SH and PD signal, respectively, obtained from any one of the joint recesses or from any joint evaluated in the elbow or the wrist.

Tenosynovitis on B-mode and PD signal was defined and scored separately, semiquantitively according to the OMERACT on a scale of $0-3$ (grade $0=$ none, grade $1=$ minimal, grade 2 = moderate, grade $3=$ severe) [12].

\section{Definition of ultrasound remission}

Several definitions of US remission were examined: the strictest were defined as the absence of $\mathrm{SH}, \mathrm{TS}$, and PD signal (B-mode $=0$ and PD $=0$ ) and as the absence of 
Table I. Characteristics of patients with rheumatoid arthritis in clinical remission

\begin{tabular}{|c|c|}
\hline Variable & Patients $(n=37)$ \\
\hline Gender, female $[n(\%)]$ & $27(73)$ \\
\hline Age [years, mean $\pm S D$ (range)] & $54.2 \pm 12.7(22-77)$ \\
\hline Smoking $[n(\%)]$ & $8(21)$ \\
\hline Body mass index $\left[\mathrm{kg} / \mathrm{m}^{2}, \pm \mathrm{SD}\right.$ (range)] & $29.5 \pm 5.4(19.9-41.2)$ \\
\hline $\begin{array}{l}\text { Disease duration [years, mean } \pm \text { SD } \\
\text { (range)] }\end{array}$ & $8.1 \pm 5.1(1-28)$ \\
\hline $\begin{array}{l}\text { Remission duration [months, } \pm \text { SD } \\
\text { (range)] }\end{array}$ & $36.5 \pm 32.7(6-12)$ \\
\hline $\begin{array}{l}\text { Patient pain assessment (0-10), } \\
\text { median (range) }\end{array}$ & $1(0-4)$ \\
\hline $\begin{array}{l}\text { Patient global assessment (0-10), } \\
\text { median (range) }\end{array}$ & $1(0-4)$ \\
\hline $\begin{array}{l}\text { Tender joint count (0-28), } \\
\text { median (range) }\end{array}$ & $0(0-2)$ \\
\hline $\begin{array}{l}\text { Swollen joint count (0-28), } \\
\text { median (range) }\end{array}$ & $0(0-1)$ \\
\hline $\mathrm{ESR}[\mathrm{mm} / \mathrm{h}$, mean $\pm \mathrm{SD}]$ & $20.6 \pm 12.2$ \\
\hline $\mathrm{CRP}[\mathrm{mm} / \mathrm{h}$, mean $\pm \mathrm{SD}]$ & $4.4 \pm 4.4$ \\
\hline RF positive $[n(\%)]$ & $62 \%(n=22 / 35)$ \\
\hline ACPA positive $[n(\%)]$ & $75 \%(n=25 / 33)$ \\
\hline DAS28 [mean \pm SD (range)] & $2.1 \pm 0.5(0.49-2.6)$ \\
\hline SDAI $[n(\%)]$ & $26(70.2)$ \\
\hline $\operatorname{CDAI}[n(\%)]$ & $24(64.8)$ \\
\hline ACR/EULAR Boolean criteria [ $n(\%)]$ & $20(54)$ \\
\hline $\begin{array}{l}\text { Presence of erosions in radiographs } \\
{[n(\%)]}\end{array}$ & $30(81)$ \\
\hline Corticosteroids [ $n(\%)]$ & $26(70.3)$ \\
\hline bDMARD $[n(\%)]$ & $6(16.2)$ \\
\hline
\end{tabular}

ACPA - anti-citrullinated peptide antibodies, ACR/EULAR - American College of Rheumatology/European League Against Rheumatism, $D D M A R D$ - biologic disease-modifying anti-rheumatic drugs, $C D A I$ - clinical disease activity index, CRP - C-reactive protein, DAS28 - disease activity score, ESR - erythrocyte sedimentation, $R F$ - rheumatoid factor, SD - standard deviation, SDAI - simple disease activity index. ACR/EULAR Boolean remission criteria - tender and swollen joint counts $\leq 1, C R P \leq 10 \mathrm{mg} / \mathrm{dl}$ and patient global assessment $\leq 1$

$\mathrm{SH}$ and $\mathrm{PD}$ signal $(\mathrm{SH}=0$ and $\mathrm{PD}=0)$. Less strict criteria were used $(\mathrm{SH} \leq 1$ and $\mathrm{PD}=0$ or $\mathrm{SH} \leq 1$ and $\mathrm{PD} \leq 1)$. Others were based solely on synovial PD (absent $[P D=0]$ or low level $[P D \leq 1])$.

\section{Statistical analysis}

Statistical analysis was performed using SPSS version 17. Quantitative variables were expressed as the mean \pm standard deviation (SD) or median and range. Categorical variables were presented as absolute frequencies and percentages.

\section{Results}

\section{Demographic and clinical characteristics}

Thirty-seven patients were enrolled in the study. The demographic and clinical features are presented in Tablel. The mean age was 54.2 years, and $73 \%$ were females. The mean disease duration was 8.1 years, and the mean remission duration was 36.5 months. The rate of remission according to the different composite indices was $70.2 \%$ for the SDAI, $64.8 \%$ for the CDAI, and $54 \%$ for the ACR/EULAR Boolean criteria.

\section{Ultrasound synovitis and tenosynovitis}

Synovial hypertrophy was detected in $94.6 \%$ of patients. The grades of $\mathrm{SH}$ were as follows: 1 in $89.1 \%$, 2 in $64.8 \%$, and 3 in $16.2 \%$ of patients. The wrist, MTP2, MCP3, MCP2, and knee $(78.3,45.9,43.2$, 40.5, and 37.8\%, respectively) were predominantly involved.

Power Doppler signal was objectified in $59.5 \%$ of patients. The grades of PD were: 1 in 37.8\%, 2 in 35.1\%, and 3 in $5.4 \%$ of patients. The wrist, MCP2, MCP3, and MTP2 joints $(40.5,18.9,10.8$, and $8.5 \%$, respectively) were frequently involved.

On B-mode, TS was detected in $40.5 \%$ of patients. It was most commonly grade 1 in $32.4 \%, 2$ in $10.8 \%$, and 3 in $2.7 \%$ of patients. B-mode TS was observed in the extensor carpi ulnaris, tibialis posterior, peroneal, flexor digitorum, and extensor digitorum carpi (21.6, 10, 8.1, 5.4 , and $2.7 \%$, respectively).

Tenosynovitis with PD was evident in $13.5 \%$ of patients. Grade 2 (10.8\%) was more common than grade 1 (5.4\%). It affected predominantly the extensor carpi ulnaris in $8.1 \%$ and in $2.7 \%$ the tibialis posterior, peroneal (Fig. 1), and extensor digitorum carpi.

\section{Ultrasound remission}

Among our patients, US remission was rare in 5.4\% $(n=2)$ of patients when the strict criteria were used at the joint and tendon level. Ultrasound remission was recorded in $32.4 \%$ of patients if the grade of $\mathrm{SH}$ and $\mathrm{PD}$ was $\leq 1$ at the joint level, in $40.5 \%$ of patients in the absence of PD, and in $62.2 \%$ of patients if the PD grade was $\leq 1$ at the joint level. At the tendons level, US remission varied from 51.4 to $85 \%$ of patients.

For the other clinical remission criteria, US remission at joints and tendons was found in 7.7-60\% of patients. Globally, the percentage of US remission varied according to the clinical and US remission criteria, as illustrated in Table II.

\section{Discussion}

This study investigated US remission in many joints and tendons using different definitions of clinical and 


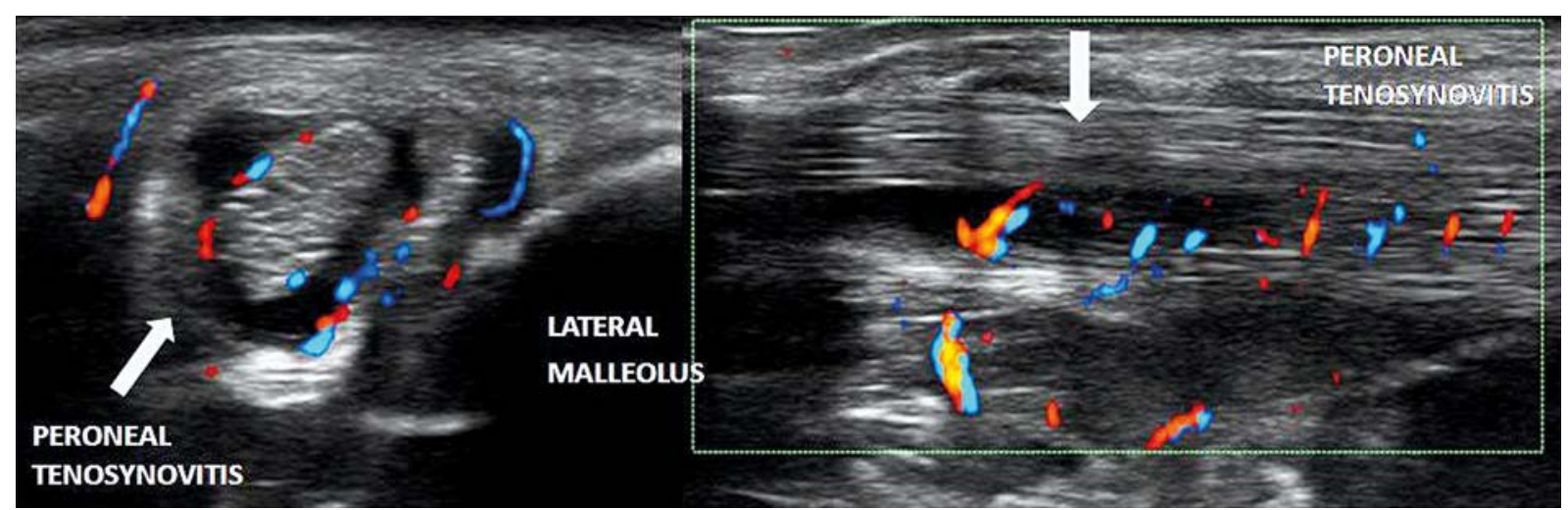

Fig. 1. Transverse and longitudinal section of the peroneal tendons showing grade 3 tenosynovitis in B-mode with grade 2 power Doppler.

Table II. Ultrasound remission in clinical remission according to disease activity score, clinical disease activity index, simple disease activity index, and American College of Rheumatology/European League Against Rheumatism Boolean criteria in rheumatoid arthritis

\begin{tabular}{|c|c|c|c|}
\hline Grade (\%) & Synovitis & Tenosynovitis & $\begin{array}{c}\text { Synovitis } \\
\text { and tenosynovitis }\end{array}$ \\
\hline \multicolumn{4}{|l|}{ DAS28-ESR $(n=37)$} \\
\hline B-mode + PD $=0$ & 5.4 & 51.4 & 5.4 \\
\hline B-mode $\leq 1$ and $P D=0$ & 32.4 & 75.5 & 32.4 \\
\hline B-mode $\leq 1$ and $\mathrm{PD} \leq 1$ & 32.4 & 75.5 & 35.1 \\
\hline $\mathrm{PD}=0$ & 40.5 & 78.4 & 37.8 \\
\hline$P D \leq 1$ & 62.2 & 83.8 & 59.5 \\
\hline \multicolumn{4}{|l|}{ SDAI $(n=26)$} \\
\hline B-mode $+P D=0$ & 7.7 & 57.7 & 7.7 \\
\hline B-mode $\leq 1$ and $\mathrm{PD}=0$ & 38.5 & 76.9 & 38.5 \\
\hline B-mode $\leq 1$ and $\mathrm{PD} \leq 1$ & 38.5 & 76.9 & 38.5 \\
\hline$P D=0$ & 42.3 & 80.8 & 42.3 \\
\hline$P D \leq 1$ & 57.7 & 80.8 & 53.8 \\
\hline \multicolumn{4}{|l|}{ CDAI $(n=24)$} \\
\hline B-mode $+P D=0$ & 8.3 & 58.3 & 8.3 \\
\hline B-mode $\leq 1$ and PD $=0$ & 41.7 & 79.2 & 41.7 \\
\hline$\underline{B}$-mode $\leq 1$ and $P D \leq 1$ & 41.7 & 79.2 & 41.7 \\
\hline $\mathrm{PD}=0$ & 45.8 & 83.3 & 45.8 \\
\hline$P D \leq 1$ & 54.2 & 83.3 & 50 \\
\hline \multicolumn{4}{|c|}{ ACR/EULAR Boolean criteria $(n=20)$} \\
\hline$\underline{B}$-mode $+P D=0$ & 10 & 70 & 10 \\
\hline B-mode $\leq 1$ and $P D=0$ & 35 & 85 & 35 \\
\hline B-mode $\leq 1$ and $P D \leq 1$ & 35 & 85 & 35 \\
\hline$P D=0$ & 40 & 85 & 40 \\
\hline $\mathrm{PD} \leq 1$ & 60 & 85 & 55 \\
\hline
\end{tabular}

ACR/EULAR - American College of Rheumatology/European League Against Rheumatism, CDAl - clinical disease activity index, DAS28 - disease activity score, ESR - erythrocyte sedimentation rate, $P D$ - power Doppler, SDAI - simple disease activity index. $A C R / E U L A R$ Boolean remission criteria - tender and swollen joint counts $\leq 1, C R P \leq 10 \mathrm{mg} / \mathrm{dl}$ and patient global assessment $\leq 1$,

$B$-mode $+P D=0$ - the absence of signal on $B$-mode and $P D, B$-mode $\leq 1$ and $P D=0$ - a grade $\leq 1$ on $B$-mode and $a P D=0, B$-mode $\leq 1$ and $P D \leq 1-$ a grade $\leq 1$ on $B$-mode and $P D, P D=0$ - the absence of $P D, P D \leq 1$ - a grade $\leq 1$ of $P D$. 
US remission. We have shown that a significant number of RA patients in clinical remission had synovitis (94.6\%) and TS (40.5\%) in B-mode with PD signal (59.5 and $13.5 \%$, respectively). Ultrasound remission at joints and tendons was confirmed in $5.4-62.2 \%$ of patients. In addition to DAS28-ESR, all the other remission criteria showed US inflammatory activity. According to the literature and our study, clinical remission, even classified by strict composite indices, does not seem to reflect the "true" remission.

Indeed, SH was detected in $20-100 \%$ of patients, and $12.8-93.3 \%$ had at least one synovitis with PD, in the literature [5, 13-16]. B-mode TS was found in 9.6-52.3\% of patients and PD mode in $2.1-26 \%$ of patients $[15,17-20]$. In sustained remission, TS with PD was absent in 2 studies, suggesting its importance in US evaluation during remission [21, 22]. Filippou et al. [20] showed that $80.9 \%$ of patients with RA in remission had at least one synovitis or TS in B-mode, with PD in 51\% of patients.

Moreover, SH and PD were predictive of flare in patients with clinical remission [6]. Progressive bone erosion was associated mainly with PD and severe grades of $\mathrm{SH}$ as demonstrated by some studies [23]. Likewise, TS with PD predicts the risk of flare, unstable remission $[18,21]$, and radiographic damage progression [24]. However, US remission is still not consensual throughout the different definitions available (Table III).

Some authors defined it as an absence of joints with PD signal [7, 25-28]. Others accepted a more stringent definition, which requires the absence of $\mathrm{SH}$ and $\mathrm{PD}$ [18, 25, 29-32].

Saleem et al. [25] accepted a minimal amount of synovitis and defined US remission as a grade of $\mathrm{SH}$ and $P D \leq 1$ for each scanned joint, and several authors accepted a minimal residual PD signal (total PD activity score $\leq 1)[25,33]$. However, these studies assessed synovitis only.

Other studies were focused on joint sites as a whole, including the joints and adjacent tendons most affected in RA [20,34]. However, these studies are infrequent. In the Italian STARTER study, including 361 patients, synovitis and TS were considered in the presence of grade $\geq 1$ in B-mode or PD [20]. This study demonstrated that tendon and joint US can be useful in assessing the variation of the inflammatory activity in RA in clinical remission [20]. The study by Harman et al. [34], involving 64 patients, also assessed US remission in the joints and tendons.

Our study population showed less US remission than in the literature (Table III) except for the definition grade $\leq 1$ of PD. These results can be related to the number of joints and tendons included, the clinical definitions of remission used, stringently treatment strategies, differences in the applied scoring systems, and the existence of factors influencing US remission like duration of RA and remission or erosive RA.

In the literature, US remission varied between 0 and $78 \%$ in clinical remission (DAS28-ESR) (Table III). The synovial hypertrophy and PD was absent in $0-51.1 \%$ of patients [18, 25, 29-32, 34-36]. Ultrasound remission defined by grade $\leq 1$ of $\mathrm{SH}$ and the absence of PD was seen in $33-58 \%$ of patients [36, 37], and in $56 \%$ if the PD had a grade $\leq 1$ [25]. Joint PD was absent in 42 to $58 \%[25,26,33,36]$. A grade $\leq 1$ of PD was reported in 62 to $78 \%$ [33].

In these studies, US remission was sought only in the joints. Vlad et al. [22] reported that all tendons showed US remission. In another study, SH, B-mode TS, and PD were absent in 43.9-49.6\% of patients [34]. A second study did not find B-mode synovitis and TS in $19.1 \%$ of patients and PD mode in $49 \%$ of patients [20].

This study underlines the role of US in clinical practice because even the stringent clinical remission criteria could not totally reflect the "true" remission in a large number of joints and tendons. Moreover, its role in RA remission management has been a subject of debate in recent years $[28,38]$. Recently, US was recommended during follow-up in some situations or during treatment tapering in clinical remission by the GEISPER French group [39]. The therapeutic decision was considered in the presence of synovitis or TS with Doppler signal.

\section{Study limitations}

The present study has several limitations. The first was the small number of patients. However, this is a convenience sampling of patients in remission over a period of one year. Secondly, we aimed to explore the maximum number of joints, but some sites such as the hip are difficult to assess with a US probe whose frequency is above $6 \mathrm{MHz}$. Thirdly, US is an operator-dependent imaging technique. However, it was improved by a standardized imaging acquisition technique and performed by an experienced rheumatologist. Finally, a subsequent follow-up to detect relapses and radiographic progression, and correlate them to the results of US data would be of interest in defining US remission.

\section{Conclusions}

The present study confirms data from previous studies on the persistence and frequency of synovitis and TS in B-mode and PD in RA in clinical remission. All the remission criteria, even when classified as strict, showed inflammatory activity. The frequency of US remission varies from 5.4 to $62.2 \%$ depending on the US definitions and activity indices used. 


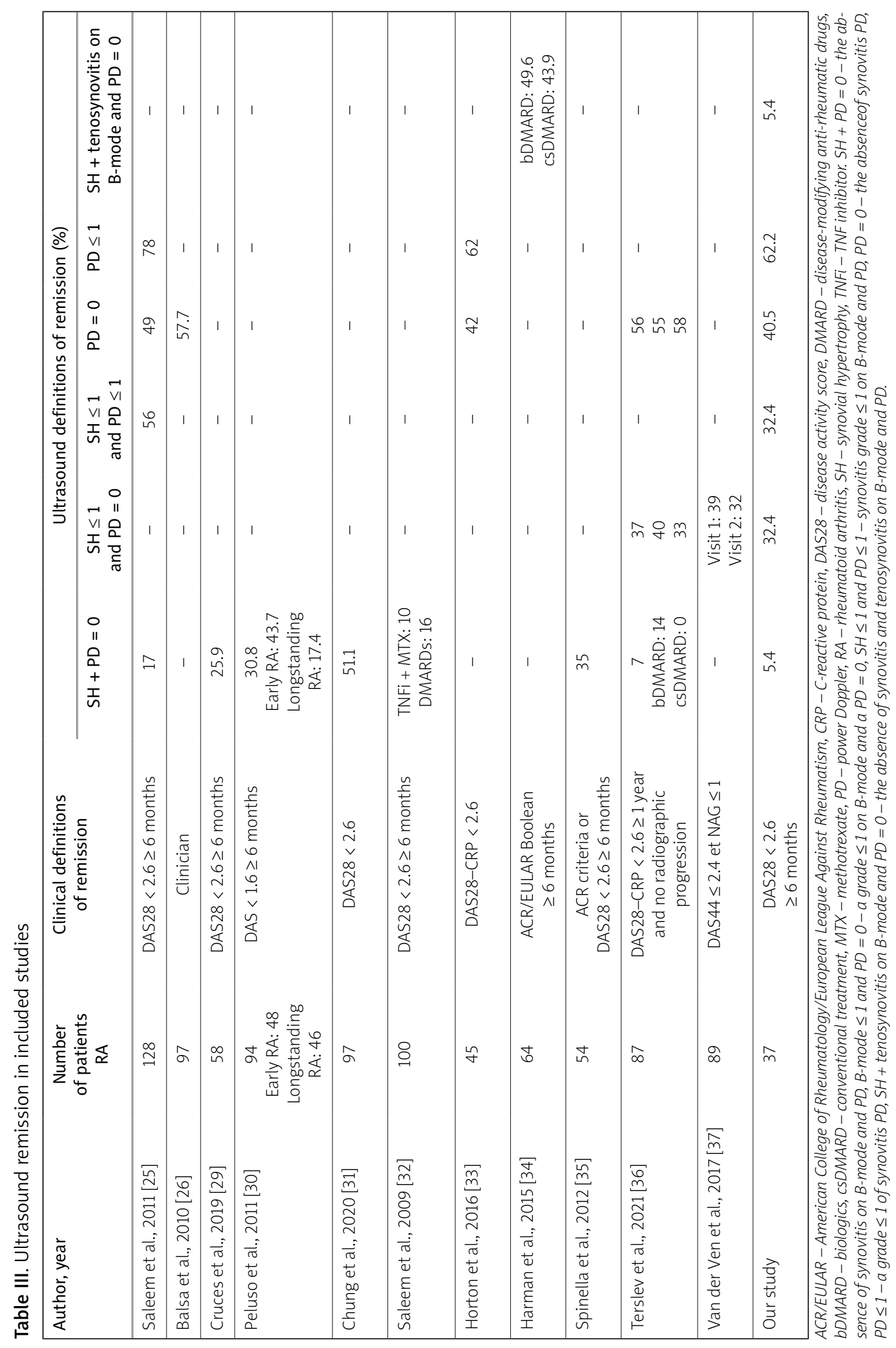


Further studies are needed to assess whether these findings are also associated with clinically and radiographically significant outcomes.

The authors declare no conflict of interest.

\section{References}

1. Aletaha D, Smolen JS. Diagnosis and management of rheumatoid arthritis: a review. JAMA 2018; 320: 1360-1372, DOI: 10.1001/jama.2018.13103.

2. Smolen JS, Landewé RBM, Bijlsma JWJ, et al. EULAR recommendations for the management of rheumatoid arthritis with synthetic and biological disease-modifying antirheumatic drugs: 2019 update. Ann Rheum Dis 2020; 79: 685-699, DOI: 10.1136/annrheumdis-2019-216655.

3. Haavardsholm EA, Lie E, Lillegraven S. Should modern imaging be part of remission criteria in rheumatoid arthritis? Best Pract Res Clin Rheumatol 2012; 26: 767-785, DOI: 10.1016/j. berh.2012.10.004.

4. Kuettel D, Terslev L, Weber U, et al. Flares in rheumatoid arthritis: do patient-reported swollen and tender joints match clinical and ultrasonography findings? Rheumatology (Oxford) 2020; 59: 129-136, DOI: 10.1093/rheumatology/kez231.

5. Mouterde G, Morel J. [Place de l'échographie dans la polyarthrite rhumatoïde en remission]. Revue du rhumatisme monographies 2015; 82: 225-232, DOI: 10.1016/j.monrhu.2015.04.003 [Article in French].

6. Han J, Geng Y, Deng X, Zhang Z. Subclinical synovitis assessed by ultrasound predicts flare and progressive bone erosion in rheumatoid arthritis patients with clinical remission: a systematic review and metaanalysis. J Rheumatol 2016; 43: 2010-2018, DOI: 10.3899/jrheum.160193.

7. Geng Y, Wang L, Zhang X, et al. Treat-to-target strategies aiming at additional ultrasound remission is associated with better control of disease activity and less flare in rheumatoid arthritis. Clin Rheumatol 2021; 40: 113-121, DOI: 10.1007/ s10067-020-05186-1.

8. Acebes C, Andreu JL, Balsa A, et al. "There is something you must see": breaking down the remission concept in rheumatoid arthritis from a rheumatologist's perspective. Clin Exp Rheumatol 2020; 38: 82-87.

9. Aletaha D, Neogi T, Silman AJ, et al. 2010 Rheumatoid arthritis classification criteria: an American College of Rheumatology/ European League Against Rheumatism collaborative initiative. Arthritis Rheum 2010; 62: 2569-2581, DOI: 10.1002/art.27584.

10. van der Heijde DM, van Leeuwen MA, van Riel PL, van de Putte LB. Radiographic progression on radiographs of hands and feet during the first 3 years of rheumatoid arthritis measured according to Sharp's method (van der Heijde modification). J Rheumatol 1995; 22: 1792-1796.

11. D'Agostino MA, Terslev L, Aegerter P, et al. Scoring ultrasound synovitis in rheumatoid arthritis: a EULAR-OMERACT ultrasound taskforce - Part 1: definition and development of a standardised, consensus-based scoring system. RMD Open 2017; 3: e000428, DOI: 10.1136/rmdopen-2016-000428.
12. Naredo E, D'Agostino MA, Wakefield RJ, et al. Reliability of a consensus-based ultrasound score for tenosynovitis in rheumatoid arthritis. Ann Rheum Dis 2013; 72: 1328-1334, DOI: 10.1136/annrheumdis-2012-202092.

13. Karimzadeh $\mathrm{H}$, Karami $\mathrm{M}$, Bazgir $\mathrm{N}$, et al. Ultrasonographic findings of rheumatoid arthritis patients who are in clinical remission. J Res Med Sci 2018; 23: 38, DOI: 10.4103/jrms. JRMS_308_17.

14. Gärtner M, Mandl P, Radner H, et al. Sonographic joint assessment in rheumatoid arthritis: associations with clinical joint assessment during a state of remission. Arthritis Rheum 2013; 65: 2005-2014, DOI: 10.1002/art.38016.

15. Ventura-Ríos L, Sánchez Bringas G, Hernández-Díaz C, et al. Subclinical synovitis and tenosynovitis by ultrasonography (US) 7 score in patients with rheumatoid arthritis treated with synthetic drugs, in clinical remission by DAS28. Reumatol Clin 2019; 15: e5-e9, DOI: 10.1016/j.reuma.2017.10.011 [Article in English, Spanish].

16. Yoshimi R, Hama M, Takase $\mathrm{K}$, et al. Ultrasonography is a potent tool for the prediction of progressive joint destruction during clinical remission of rheumatoid arthritis. Mod Rheumatol 2013; 23: 456-465, DOI: 10.1007/s10165-012-0690-1.

17. Brown AK, Quinn MA, Karim Z, et al. Presence of significant synovitis in rheumatoid arthritis patients with disease-modifying antirheumatic drug-induced clinical remission: evidence from an imaging study may explain structural progression. Arthritis Rheum 2006; 54: 3761-3773, DOI: 10.1002/art.22190.

18. Bellis E, Scirè CA, Carrara G, et al. Ultrasound-detected tenosynovitis independently associates with patient-reported flare in patients with rheumatoid arthritis in clinical remission: results from the observational study STARTER of the Italian Society for Rheumatology. Rheumatology (Oxford) 2016; 55: 1826-1836, DOI: 10.1093/rheumatology/kew258.

19. Baker KF, Thompson B, Lendrem DW, et al. Lack of association between clinical and ultrasound measures of disease activity in rheumatoid arthritis remission. Ther Adv Musculoskel Dis 2020; 12: 1759720X20915322, DOI: 10.1177/1759720X20915322.

20. Filippou G, Sakellariou G, Scirè CA, et al. The predictive role of ultrasound-detected tenosynovitis and joint synovitis for flare in patients with rheumatoid arthritis in stable remission. Results of an Italian multicentre study of the Italian Society for Rheumatology Group for Ultrasound: the STARTER study. Ann Rheum Dis 2018; 77: 1283-1289, DOI: 10.1136/annrheumdis-2018-213217.

21. Janta I, Valor L, De la Torre I, et al. Ultrasound-detected activity in rheumatoid arthritis on methotrexate therapy: which joints and tendons should be assessed to predict unstable remission? Rheumatol Int 2016; 36: 387-396, DOI: 10.1007/s00296015-3409-8

22. Vlad V, Berghea F, Micu M, et al. Tenosynovitis US scoring systems follow synovitis and clinical scoring systems in RA and are responsive to change after biologic therapy. Med Ultrason 2015; 17: 352-360, DOI: 10.11152/mu.2013.2066.173.viv.

23. Tan YK, Li H, Allen JC, Thumboo J. Joint damage in rheumatoid arthritis: lessons learned from an extended 36-joint ultrasonography and 28-joint Disease Activity Score assessments. Int J Rheum Dis 2021; 24: 106-111, DOI: 10.1111/1756185X.14013. 
24. Lillegraven S, Bøyesen P, Hammer HB, et al. Tenosynovitis of the extensor carpi ulnaris tendon predicts erosive progression in early rheumatoid arthritis. Ann Rheum Dis 2011; 70: 2049-2050, DOI: 10.1136/ard.2011.151316.

25. Saleem B, Brown AK, Keen $H$, et al. Should imaging be a component of rheumatoid arthritis remission criteria? A comparison between traditional and modified composite remission scores and imaging assessments. Ann Rheum Dis 2011; 70 792-798, DOI: 10.1136/ard.2010.134445.

26. Balsa A, de Miguel E, Castillo C, et al. Superiority of SDA over DAS28 in assessment of remission in rheumatoid arthritis patients using power Doppler ultrasonography as a gold standard. Rheumatology (Oxford) 2010; 49: 683-690, DOI: 10.1093/rheumatology/kep442.

27. Dejaco C, Duftner C, Wipfler-Freissmuth E, et al. Ultrasound-defined remission and active disease in rheumatoid arthritis: association with clinical and serologic parameters. Semin Arthritis Rheum 2012; 41: 761-767, DOI: 10.1016/j. semarthrit.2011.09.005.

28. Haavardsholm EA, Aga AB, Olsen IC, et al. Ultrasound in management of rheumatoid arthritis: ARCTIC randomised controlled strategy trial. BMJ 2016; 354: i4205, DOI: 10.1136/bmj. i4205.

29. Cruces M, Al Snih S, Serra-Bonett N, Rivas JC. Subclinical synovitis measured by ultrasound in rheumatoid arthritis patients with clinical remission induced by synthetic and biological modifying disease drugs. Reumatol Clin (Engl Ed) 2019; 15 218-222, DOI: 10.1016/j.reuma.2017.08.004 [Article in English, Spanish].

30. Peluso G, Michelutti A, Bosello S, et al. Clinical and ultrasonographic remission determines different chances of relapse in early and long standing rheumatoid arthritis. Ann Rheum Dis 2011; 70: 172-175, DOI: 10.1136/ard.2010.129924.

31. Chung SW, Choi JY, Lee SH, et al. Predicting imaging remission in rheumatoid arthritis: a case-control ultrasound study. J Korean Med Sci 2020; 35: e260, DOI: 10.3346/jkms.2020.35. e260.
32. Saleem B, Brown AK, Keen $\mathrm{H}$, et al. Disease remission state in patients treated with the combination of tumor necrosis factor blockade and methotrexate or with disease-modifying antirheumatic drugs: a clinical and imaging comparative study. Arthritis Rheum 2009; 60: 1915-1922, DOI: 10.1002/art.24596.

33. Horton SC, Tan AL, Freeston JE, et al. Discordance between the predictors of clinical and imaging remission in patients with early rheumatoid arthritis in clinical practice: implications for the use of ultrasound within a treatment-to-target strategy. Rheumatology (Oxford) 2016; 55: 1177-1187, DOI: 10.1093/ rheumatology/kew037.

34. Harman H, Tekeoğlu I, Kaban N, Harman S. Factors influencing ultrasonographic remission in patients with rheumatoid arthritis. Rheumatol Int 2015; 35: 485-491, DOI: 10.1007/ s00296-014-3177-x.

35. Spinella A, Sandri G, Carpenito G, et al. The discrepancy between clinical and ultrasonographic remission in rheumatoid arthritis is not related to therapy or autoantibody status. Rheumatol Int 2012; 32: 3917-3921, DOI: 10.1007/s00296011-2259-2.

36. Terslev L, Brahe CH, Østergaard M, et al. Using a DAS28-CRPsteered treat-to-target strategy does not eliminate subclinical inflammation as assessed by ultrasonography in rheumatoid arthritis patients in longstanding clinical remission. Arthritis Res Ther 2021; 23: 48, DOI: 10.1186/s13075-021-02426-w.

37. Van der Ven M, Kuijper TM, Gerards AH, et al. No clear association between ultrasound remission and health status in rheumatoid arthritis patients in clinical remission. Rheumatology (Oxford) 2017; 56: 1276-1281, DOI: 10.1093/rheumatology/ kex080.

38. Dale J, Stirling A, Zhang R, et al. Targeting ultrasound remission in early rheumatoid arthritis: the results of the TaSER study, a randomised clinical trial. Ann Rheum Dis 2016; 75: 1043-1050, DOI: 10.1136/annrheumdis-2015-208941.

39. Mouterde G, Gandjbakhch F, Le Goff B, et al. Recommendations for the pragmatic use of ultrasound in rheumatoid arthritis by the GEISPER French group. Joint Bone Spine 2021; 88: 105187, DOI: 10.1016/j.jbspin.2021.105187. 